\title{
A dinâmica da cadeia produtiva do ensino superior privado brasileiro
}

A educação é um segmento muito importante para contribuir com a melhoria da qualidade de vida de uma população, bem como da construção de um país inovador. Embora exista uma estrutura no Brasil, esta pode ser discutida acerca do seu papel, bem como da integração que deveria existir entre os níveis de ensino existentes, bem como os componentes da mesma. Assim, a proposta deste artigo é apresentar a estrutura atual da educação no país e construir a cadeia produtiva da educação, evidenciando como a mesma é formada e seu papel relevante. Conforme foi visto pela estrutura da educação no país, há desafios existentes que consideram tanto a esfera pública como a privada. A predominância do meio privado em número de instituições de ensino e no número de alunos não é visto como um papel importante e muitas vezes essas instituições sofrem com mudanças legais que ocorrem a todo e qualquer momento.

Palavras-chave: Educação; Cadeia produtiva; Ambiente; Componentes.

\section{The dynamics of the productive chain of Brazilian private higher education}

\begin{abstract}
Education is a very important segment to contribute to improving the quality of life of a population, as well as building an innovative country. Although there is a structure in Brazil, it can be discussed about its role, as well as the integration that should exist between the existing levels of education, as well as the components of it. Thus, the purpose of this article is to present the current structure of education in the country and build the education production chain, showing how it is formed and its relevant role. As seen by the structure of education in the country, there are existing challenges that consider both the public and private spheres. The predominance of the private sector in the number of educational institutions and the number of students is not seen as an important role and often these institutions suffer from legal changes that occur at any time.
\end{abstract}

Keywords: Education; Productive chain; Environment; Components.

Topic: Ensino Superior, Pesquisa e Extensão

Reviewed anonymously in the process of blind peer.
Received: $15 / 01 / 2020$

Approved: $20 / 04 / 2020$
Fabricio Pelloso Piurcosky (iD

Universidade Federal de Lavras, Brasil

http://lattes.cnpq.br/9736654155430529

http://orcid.org/0000-0001-5458-5129

fabricio@unis.edu.br

Sheldon William Silva

Instituto Federal de Minas Gerais, Brasil http://lattes.cnpq.br/5691436224279198

http://orcid.org/0000-0002-2473-5728

sheldonwilliamsilva@gmail.com

Rodrigo Franklin Frogeri

Centro Universitário do Sul de Minas, Brasil

http://lattes.cnpq.br/0403458828547468

http://orcid.org/0000-0002-7545-7529

rodrigo.frogeri@unis.edu.br
Pedro dos Santos Portugal Júnior

Centro Universitário do Sul de Minas, Brasil

http://lattes.cnpq.br/3402598684545658

http://orcid.org/0000-0003-2590-1959

pedrorotaract@hotmail.com
Referencing this:

PIURCOSKY, F. P.; SILVA, S. W.; FROGERI, R. F.; PORTUGAL JÚNIOR, P. S.. A dinâmica da cadeia produtiva do ensino superior privado brasileiro. Humanum Sciences, v.2, n.1, p.1-12, 2019. DOI: http://doi.org/10.6008/CBPC2674-6654.2020.001.0001 


\section{INTRODUÇÃO}

A educação possui um papel de vital importância para a evolução de uma sociedade. Diversos países investem maciçamente com objetivo de estabelecer diferenciais a partir dos recursos humanos que são formados. Essa relevância é sempre postulada como uma verdade fundamental que pode alterar completamente a realidade social das pessoas e oportunizar caminhos diferentes para melhoria da qualidade de vida de uma população. Ao mesmo tempo, trata-se de uma área que apresenta desafios dada a dinâmica do mercado e as exigências de formação profissional, pois é um processo que está inserido na globalização, e, portanto, acompanha as novidades e necessidades que surgem.

Por se tratar de uma área que pode ofertar diversos produtos para faixas etárias distintas é um mercado atrativo e em expansão em muitos países. No entanto, tem seus desafios, como, por exemplo, o atual cenário econômico-financeiro do Brasil que tem apresentado um panorama instável, o que faz com que as instituições de ensino ou grupos educacionais (de capital aberto ou não) reflitam continuamente sobre as suas estratégias. Isso tem se tornado obrigatório, uma vez que o mercado educacional brasileiro passou por 174 eventos de fusões, aquisições e alianças entre 2001 e 2015, teve a entrada de fundos de investimento de 7 países distintos e envolveu mais de 13 milhões de alunos. Somente entre 2014 e 2016 houve um aumento de 220 mil alunos, retratando um mercado em expansão, mesmo com diminuição de incentivos e um aumento no número de desempregados.

No entanto, é preciso perceber se mesmo com a expansão, a entrada de grupos internacionais e os investimentos fazem com que o egresso da educação esteja preparado para adentrar ao mercado de trabalho. Afinal, a educação além de formar o cidadão, ela também tem por objetivo formar o trabalhador e, isso, deve ser algo que inicia nos níveis básicos e não apenas no superior. Entender plenamente como acontece o processo educacional é de fundamental importância para perceber as variáveis que contribuem e as que faltam para fazer com que a educação realmente consiga transformar a realidade de um país. Para tal, é relevante perceber como a situação atual da educação foi construída. Dessa forma, o artigo possui a proposta de construir a cadeia produtiva da educação.

\section{REVISÃO TEÓRICA}

\section{Educação no Brasil}

O primeiro esforço em adequar as necessidades do Brasil ao processo de globalização teve início em 1995, com o Plano Diretor da Reforma do Aparelho do Estado. Este tinha por objetivo fazer com que a educação fosse um serviço competitivo e não exclusividade de entidades públicas. Em 1996 foi instituída a Lei de Diretrizes e Bases da Educação Brasileira (LDB 9394-96), essa teve por objetivo regulamentar o sistema educacional (público ou privado) tanto da educação básica como do ensino superior. Ela reafirma o direito à educação, garantido pela Constituição Federal e ainda, estabelece os princípios da educação e os deveres do Estado em relação à educação escolar pública, definindo as responsabilidades, em regime de colaboração, entre a União, os Estados, o Distrito Federal e os Municípios. Ela ainda estabelece os níveis da educação, 
dividindo em Educação básica e Ensino Superior.

De 2011 a 2013 houve uma grande empreitada em termos de atualizar as estruturas da educação. Porém, isso ocorreu sem levar em conta a continuidade e o próprio mercado em si. Isso pode ser comprovado pelo grande número de leis, decretos e portarias. Estes atuaram na regulação do trabalho docente, dos currículos e nos instrumentos de avaliação. Neste período ganhou bastante ímpeto os programas de expansão da educação superior (Programa de Apoio ao Plano de Reestruturação e Expansão das Universidades Federais/REUNI, educação a distância (EAD) com a criação do sistema Universidade Aberta do Brasil/UAB, cursos tecnológicos de graduação, uma nova estrutura para o Fundo de Financiamento Estudantil (FIES) e a generalização das isenções fiscais, previdenciárias e de renúncia fiscal pelo Programa Universidade para Todos/PROUNI.

Os governos neoliberais - de FHC a Lula da Silva - não só mantiveram o padrão dependente de ensino superior, mas viabilizaram seu aprofundamento, como parte da estratégia burguesa para o enfrentamento da crise estrutural do capitalismo.

Ademais, de fato, as mudanças ganharam força após a redemocratização com a constituição de 1988, que trouxe o princípio de autonomia universitária. Com isso foi criado um instrumento para as instituições privadas que era a possibilidade de não estar sob a guarda do controle burocrático do antigo Conselho Federal de Educação (CFE), principalmente em relação à criação e extinção de cursos nas sedes e ao remanejamento do número de vagas oferecidas.

Dessa maneira, é possível afirmar que foi permitido, portanto, a interiorização das faculdades, com uma capilaridade maior, com a diversificação da oferta de cursos. No entanto, o artigo 10 do Decreto 2.306, de agosto de 1997 dispôs que as entidades mantenedoras poderiam assumir qualquer das formas admitidas em direito, de natureza civil e comercial, e quando constituídas como fundações serão regidas pelo Código Civil Brasileiro (art. 24). Isso significava que as mantenedoras das instituições de ensino superior poderiam alterar seus estatutos e escolher assumir natureza civil ou comercial. Além dessas mudanças legais, a Lei de Diretrizes e Bases da Educação (LDB), em 1996, permitiu as IES a possibilidade de poderem captar recursos abrindo seu capital na bolsa de valores.

Dessa forma, ficou estabelecido que a Educação Básica é composta pela Educação Infantil (creches com crianças de 0 a 3 anos e pré-escolas com crianças de 4 e 5 anos) sendo de competência dos municípios; Ensino Fundamental (anos iniciais (do 1음 ao 5o ano) e anos finais (do 6으 ao 9o ano)), sendo que os municípios estão atendendo aos anos iniciais e os Estados os anos finais; e, Ensino Médio (do 10 ao 3o ano), sendo de responsabilidade dos Estados e podendo ser técnico profissionalizante, ou não. O Ensino Superior é de competência da União, que pode autorizar e fiscalizar as instituições privadas de ensino superior.

A educação brasileira possui outras modalidades: Educação Especial (atende aos educandos com necessidades especiais), Educação a distância (atende aos estudantes com a utilização de tecnologias de informação e comunicação), Educação Profissional e Tecnológica (objetivo de preparar os estudantes a exercerem atividades produtivas, atualizar e aperfeiçoar conhecimentos tecnológicos e científicos), Educação de Jovens e Adultos (pessoas que não tiveram acesso à educação na idade correta) e Educação Indígena (para as comunidades indígenas). 
O DCE divide as IES brasileiras em públicas ou privadas. As instituições públicas de ensino são mantidas pelo Poder Público em 3 formatos, quais são: (1) Federal, (2) Estadual ou (3) Municipal. São financiadas pelo Estado e não cobram matrícula ou mensalidade. As IES privadas são administradas por pessoas físicas ou jurídicas de direito privado, com ou sem finalidade de lucro. As instituições privadas sem finalidade de lucro são as: a) comunitárias, que incluem em sua entidade mantenedora representantes da comunidade; b) confessionais, que atendem a determinada orientação confessional e ideológica; c) filantrópicas, que prestam serviços à população, em caráter complementar às atividades do Estado.

Com relação ao aspecto administrativo as IES (tanto públicas como privadas) podem ser de 3 tipos, conforme DCE, citando a Lei de Diretrizes e Bases da Educação: a) Universidade: instituição acadêmica pluridisciplinar. Possui produção intelectual institucionalizada e apresenta requisitos mínimos de titulação acadêmica (um terço de mestres e doutores) e carga de trabalho do corpo docente (um terço em regime integral). Possui autonomia para criar cursos e sedes acadêmicas e administrativas, expedir diplomas, fixar currículos e número de vagas, firmar contratos, acordos e convênios; b) Centro Universitário: instituição pluricurricular. Pode ter uma ou mais áreas do conhecimento e não apresenta requisito da pesquisa institucionalizada; c) Faculdade: é considerada uma IES que não possui autonomia para conferir títulos e diplomas, sendo dependente com isso de uma Universidade que realize esses registros. Pode ser também um outro tipo de IES que seria uma unidade orgânica de uma Universidade. Ex.: Faculdade de Direito da Universidade Federal de Pernambuco.

\section{Dados da Educação no Brasil}

O INEP publicou a Sinopse Estatística da Educação Básica referente a 2016. Estes dados refletem a situação da área educacional do Brasil. A Educação Básica (Ensino regular (Educação Infantil, Fundamental, Médio, Profissional), Especial e Educação de Jovens e Adultos) teve 48.817.479 alunos. Destes, 8.133.040 estão no Ensino Médio regular. Pode-se adicionar a este número outros 1.342.137 são da Educação de Jovens e Adultos. Esses números refletem a quantidade de alunos e potencial para inclusão destes no ensino superior.

De acordo com os dados do INEP (2015), participaram do Exame Nacional de Desempenho de Estudantes (ENADE), um total de 1.753 IES privados em 2014. Destas, 69,5\% obtiveram conceito 3 na avaliação (os conceitos variam de 1 a 5 , sendo 5 a nota mais alta). Outros $14 \%$ obtiveram conceito 4 e apenas $0,6 \%$ obtiveram conceito 5 . Entre as que tiveram avaliações abaixo da qualidade esperada, estão os $16 \%$ restantes. Assim, é possível perceber uma concentração das IES na faixa 3, perfazendo com isso um estilo de organização que em sua maioria competem com os mesmos argumentos relacionados à qualidade e que adquirem o nível mínimo exigido. Assim, o mercado é formado por concorrentes que ofertam praticamente o mesmo tipo de serviço e que podem ser substituídos com facilidade.

Atualmente, $89,5 \%$ das IES privadas são do tipo faculdades. Estas possuem como característica um menor porte e atuam com cursos mais tradicionais. Isso favorece o tipo de mercado existente, pois possuem muita similaridade na condução do negócio. 
O atual cenário econômico-financeiro brasileiro tem sido gradativamente, atingido pela crise internacional. Isso tem gerado um efeito também no mercado educacional. Dessa forma, grupos educacionais, de capital aberto ou não precisam repensar suas estratégias e considerar neste sentido a possibilidade de um processo de F\&A. Os números de eventos neste mercado foram bastante expressivos, tendo uma participação, inclusive, de organizações estrangeiras, criando assim, grandes companhias educacionais: Kroton Educacional, Grupo Laureate, Anhanguera e Estácio Participações. O alvo desses consolidadores são as IES que atendem a classe C e D e os motivadores para tal são: ganho em escala, fortalecimento da marca e sobrevivência. Tais eventos de F\&A ganharam forte ímpeto com a criação de incentivos governamentais ao crédito universitário e ampliação de programas sociais.

Este processo de consolidação do ensino superior privado tem promovido uma reviravolta, sofrendo várias alterações. A tendência é que, embora em menor volume e velocidade, as fusões, aquisições e a formação de redes educacionais continuem a dar o tom ao já concorrido mercado do ensino superior privado brasileiro.

O mercado educacional do ensino superior brasileiro apresenta como característica o grande número de instituições privadas. Isso pode ser visto pelos números do Censo do Ensino Superior de 2016. De acordo com este estudo, há no Brasil um total de 2.407 IES, sendo que 87,7\% destas instituições são privadas. Do total de IES, $83,25 \%$ são de faculdades e deste percentual 93,11\% são IES privadas.

A distribuição geográfica das IES privadas no Brasil, de acordo com o INEP, revela que quase metade delas (46,78\%) estão na região Sudeste, sendo o estado de São Paulo com maior número (609 IES). A seguir, a região Nordeste aparece com 19,94\%, seguida de perto pela região Sul, que detém $16,82 \%$ das IES. A região Centro-Oeste possui $9,97 \%$ e a região Norte os outros $6,48 \%$.

O número total de matrículas, de acordo com o INEP, também apresenta uma grande concentração para as IES privadas. Em 2016, foram matriculados 8.048 .701 alunos no ensino superior, sendo que $75,27 \%$ (6.058.623), desse total são de alunos matriculados em IES privadas. O mesmo acontece em relação aos alunos concluintes e ingressantes. Neste mesmo ano, 1.169.449 alunos concluíram o ensino superior e 2.985.644 alunos ingressaram em IES. Destes, $78,88 \%$ dos concluintes e $82,26 \%$ dos novos entrantes são advindos de IES particulares. Dessa forma, ao observar os dados em uma perspectiva histórica a situação tem seu lado positivo e suas perspectivas negativas. Por exemplo, entre 1995 e 2016, ocorreu um crescimento no número total de matrículas (presenciais e à distância), que passou de 1.759.703, em 1995, para 8.048.701, em 2016, com um crescimento de $357 \%$. Como positivo, pode ser destacada a ampliação do acesso da população. Entretanto, é necessário perceber que a expansão se deu em uma grande parte em matrículas nas instituições privadas.

\section{Composição da estrutura e dinâmica da cadeia da educação}

Ao analisar e conhecer a estrutura de um segmento é fundamental entender os seus componentes e como estes se relacionam. Isso pode resultar em dar mais competitividade ao setor e provocar um posicionamento mais eficaz. Além disso, ao estimar os elos da cadeia, bem como a sua estrutura e dinâmica é possível atingir os agentes, o ambiente e as empresas permitindo assim ganhos ao longo da mesma 
(REZENDE et al., 2007)

O esquema da cadeia produtiva da educação tem como ponto de partida o estudo da LDB já anteriormente citada e estudos produzidos a respeito da situação atual da educação no Brasil. A Figura 1 retrata os vários organismos atuantes na educação em seus vários níveis. Atualmente, por exemplo, a educação do ensino fundamental é dada aos municípios e do ensino médio ao governo estadual. É possível perceber uma complexidade nos vários organismos envolvidos tanto na esfera federal, estadual e municipal o que faz com que em muitas situações não exista um alinhamento de ações que possa contribuir de forma lógica para a formação dos alunos. Há ainda uma discrepância muito grande no que se refere às esferas públicas em relação ao salário de professores nos níveis de atuação.

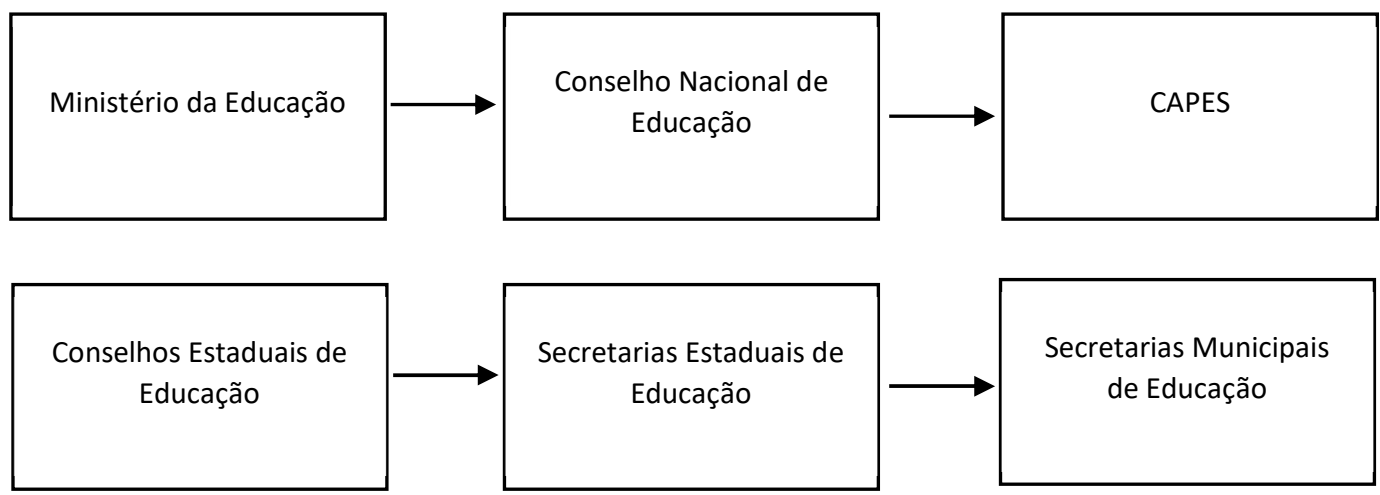

Figura 1: Componentes do sistema educacional.

A Figura 2 retrata o complexo educacional brasileiro. A sua cadeia produtiva compreende as relações do setor com seus insumos e nos mais diversos contextos. Dessa forma, é possível criar uma visão global do que está envolvido neste segmento específico.

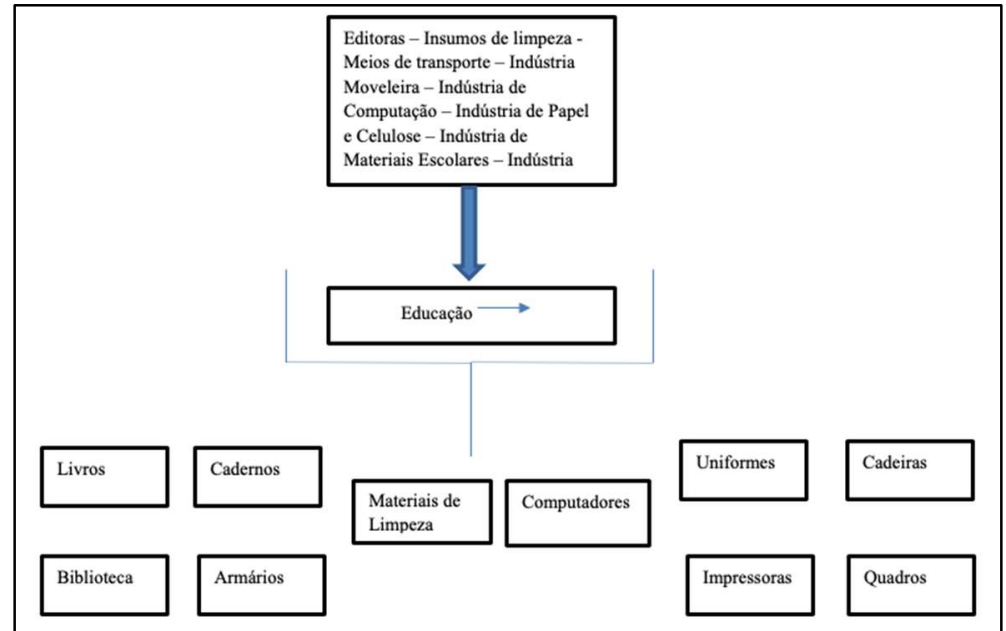

Figura 2: Esquema simplificado do complexo de Educação.

A Figura 3 retrata a cadeia produtiva da educação. Esta foi produzida tendo por base as duas figuras anteriores que em conjunto auxiliam na construção. Após o mapeamento, houve preocupação em elencar como organizar os participantes da cadeia. Isso é importante porque a concorrência é cada vez maior neste segmento e o mercado possui critérios competitivos como preço, marca, qualidade, inovação (COSTA et al., 2015). A cadeia tem como aspecto final o Ensino Superior, considerando os níveis de graduação e pós- 
graduação. Tem como aspecto inicial a educação básica que começa de forma não obrigatória com a educação infantil.

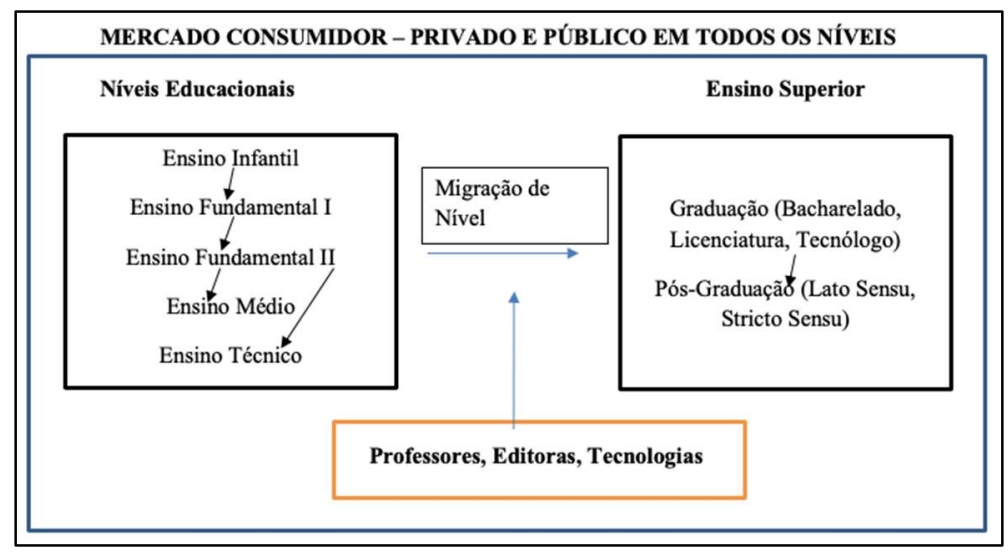

Figura 3: Estrutura da cadeia produtiva da educação.

A grande preocupação que persiste é a falta de alinhamento entre os níveis distintos de educação. Isso não deveria acontecer uma vez que não se altera por completo os insumos, os materiais e os meios para educar. Outro ponto consiste em todos os elos da cadeia - que são em parte parceiros e consumidores da educação gerada - são os parceiros do Ensino Superior. Assim, o Ensino Superior é auxiliado tanto por parceiros - neste trabalho sempre compreendidos como consumidores - com os cursos de pós-graduação (lato sensu e stricto sensu) que, tanto alunos, como docentes consomem e neles atuam, além da produção de conhecimento científico (um dos produtos da cadeia produtiva). Também é ressaltada a entrada de outros componentes como editoras, indústrias, etc.

\section{RESULTADOS E DISCUSSÃO}

\section{Análise dos resultados frente aos principais agentes, ambiente organizacional e institucional}

\section{MEC}

De acordo com o MEC (BRASIL, 2015), a história do Ministério da Educação (MEC) se inicia em 1930 com a criação do Ministério dos Negócios da Educação e Saúde Pública, no governo de Getúlio Vargas. Em 1932, houve a preocupação em elaborar um programa de política educacional amplo e integrado chamado Manifesto dos Pioneiros da Educação Nova. Este tinha uma proposta de que o Estado organizasse um plano geral de educação e definisse uma escola única, pública, laica, obrigatória e gratuita, pois a Igreja ainda dividia essa função. O sistema educacional brasileiro, até 1960, era centralizado. Com a aprovação da primeira Lei de Diretrizes e Bases da Educação (LDB), em 1961, os órgãos estaduais e municipais ganharam autonomia, com diminuição da centralização do MEC. Em 1968, houve uma reforma universitária, chamada de grande LDB da educação superior. Essa, assegurava a autonomia didático-científica, disciplinar, administrativa e financeira às universidades.

Uma nova LDB foi feita em 1971 e o ensino passou a ser obrigatório dos 7 aos 14 anos. O texto também previa um currículo comum para o primeiro e segundo graus e uma parte diversificada, em função das diferenças regionais. Uma nova reforma foi implantada em 1996, que trouxe diversas mudanças nas leis 
anteriores, com a inclusão da educação infantil (creches e pré-escola). A formação adequada dos profissionais da educação básica também teve prioridade, com um capítulo específico para tratar do assunto. Também foi criado o Fundo de Manutenção e Desenvolvimento do Ensino Fundamental e de Valorização do Magistério (Fundef). Os recursos para o Fundef vinham das receitas dos impostos e das transferências dos estados, do Distrito Federal e dos municípios vinculados à educação. Este foi substituído pelo Fundo de Manutenção e Desenvolvimento da Educação Básica e de Valorização dos Profissionais da Educação (Fundeb). Toda a educação básica, da creche ao ensino médio, passou a ser beneficiada com recursos federais. Um compromisso da União com a educação básica, que se estenderá até 2020.

Seu principal objetivo, de acordo com o site institucional é promover ensino de qualidade para nosso país. Em 2007 lançou o Plano de Desenvolvimento da Educação (PDE) como uma tentativa de estabelecer uma visão sistêmica da educação, com ações integradas e sem disputas de espaços e financiamentos. Neste PDE, o que se busca é que os investimentos na educação básica signifiquem investimento na educação profissional e na educação superior.

Trata-se de um órgão da administração federal direta e tem como área de competência a política nacional de educação; a educação infantil; a educação em geral, compreendendo ensino fundamental, ensino médio, educação superior, educação de jovens e adultos, educação profissional e tecnológica, educação especial e educação a distância, exceto ensino militar; a avaliação, a informação e a pesquisa educacionais; a pesquisa e a extensão universitárias; o magistério e a assistência financeira a famílias carentes para a escolarização de seus filhos ou dependentes.

Possui uma Carta de Serviços ao Cidadão, elaborada em consonância com as disposições do Decreto no 6.932, de 11 de agosto de 2009. Por intermédio dessa carta é refletido o compromisso com o desenvolvimento da Educação. Também elaborou seu Plano de Integração à Plataforma de Cidadania Digital, que descreve a estratégia do órgão para a transformação digital dos serviços públicos oferecidos aos seus usuários, em cumprimento ao Decreto № 8.936/16.

\section{CNE}

O Conselho Nacional de Educação (CNE) tem por missão ‘a busca democrática de alternativas e mecanismos institucionais que possibilitem, no âmbito de sua esfera de competência, assegurar a participação da sociedade no desenvolvimento, aprimoramento e consolidação da educação nacional de qualidade'. Suas atribuições são normativas, deliberativas e de assessoramento ao Ministro de Estado da Educação.

Compete ao Conselho e às Câmaras exercerem as atribuições conferidas pela Lei 9.131/95, emitindo pareceres e decidindo privativa e autonomamente sobre os assuntos que lhe são pertinentes, cabendo, no caso de decisões das Câmaras, recurso ao Conselho Pleno. Tem como compromissos: consolidar a identidade através da prática cotidiana, nas ações, intervenções e interações com os demais sistemas de ensino, a qualidade social da educação brasileira, articular e integrar as Câmaras de educação básica e de educação superior, consolidar a estrutura e diversificar o funcionamento do CNE, instaurar um diálogo efetivo, 
articulado e solidário, com todos os sistemas de ensino (em nível federal, estadual e municipal), em compromisso com a Política Nacional de Educação, em regime de colaboração e de cooperação.

\section{CAPES}

De acordo com o MEC (BRASIL, 2015), a Coordenação de Aperfeiçoamento de Pessoal de Nível Superior (Capes), é uma fundação do MEC. Procura desempenhar um papel fundamental na expansão e consolidação da pós-graduação stricto sensu (mestrado e doutorado) em todo o país. A partir de 2007, passou a atuar na formação de professores da educação básica ampliando o alcance de suas ações na formação de pessoal qualificado no Brasil e no exterior.

Suas atividades estão em avaliação da pós-graduação stricto sensu, acesso e divulgação da produção científica, investimentos na formação de recursos de alto nível no país e exterior, promoção da cooperação científica internacional, indução e fomento da formação inicial e continuada de professores para a educação básica nos formatos presencial e a distância.

CEE

De acordo com o CEE, os atuais Conselhos de Educação surgiram em 1961, com a primeira Lei de Diretrizes e Bases da Educação Nacional (Lei 4024). Tornaram-se órgãos normativos dos respectivos Sistemas de Ensino, que passaram a ser regulamentados por educadores. O CEE é órgão autônomo, com a composição, finalidade e competência estabelecidas pela legislação federal, Constituição Estadual e pela Lei Delegada no 31 , de 28.8 .85 , respeitadas as diretrizes e bases da educação nacional. Os conselheiros são nomeados pelo Governador do Estado dentre pessoas de notório saber e experiência em matéria de educação. Estes ocupam um mandato de 4 (quatro) anos, sendo permitida a recondução a critério do Governador do Estado.

O Conselho é dividido em Câmaras: do Ensino Fundamental, do Ensino Médio, Ensino Superior e de Planos e Legislação. Os Conselhos de Educação Municipais, Estaduais e Distritais, junto com o Conselho Nacional de Educação (assim denominados por leis) são todos órgãos colegiados, de caráter normativo, deliberativo e consultivo, que interpretam, deliberam, segundo suas competências e atribuições, a aplicação da legislação educacional e propõem sugestões de aperfeiçoamento nos sistemas de ensino.

\section{Associações}

Foram organizadas diversas associações relacionadas ao tema e à área Educação, as quais pode-se citar: a) Associação Brasileira das Universidades Comunitárias (ABRUC) - é uma associação que reúne as universidades comunitárias. Foi fundada em 26 de julho de 1995. Atualmente reúne 63 instituições; b) Associação das Universidades de Língua Portuguesa (AULP) - é uma entidade que congrega instituições de ensino superior de língua portuguesa no mundo. Preconiza a criação da Universidade Virtual de Língua Portuguesa, que contempla as bases de uma futura Universidade dos Países de Língua Portuguesa, no âmbito da Comunidade dos Países de Língua Portuguesa; c) Associação de Universidades Amazônicas - é uma sociedade civil, não governamental, sem fins lucrativos. Ela é definida como uma rede universitária com um 
caráter de agência de cooperação que tem como objeto e âmbito de atuação a Amazônia continental; d) Associação Nacional dos Dirigentes das Instituições Federais de Ensino Superior (Andifes) - representa oficialmente as instituições federais de ensino superior (IFES) na interlocução com o governo federal, com as associações de professores, de técnico-administrativos, de estudantes e com a sociedade em geral; e) Associação Brasileira de Educação Internacional (Faubai) - é uma organização fundada em 1988, e reúne cerca de 180 instituições de ensino superior brasileiras com o intuito de promover a integração de seus membros, além do intercâmbio e da cooperação internacional como instrumentos para a melhoria do ensino, da pesquisa, da extensão e da administração das instituições filiadas. A associação promove regularmente seminários, workshops e reuniões regionais e nacionais, além de trabalhar na divulgação das instituições que dela fazem parte junto às agências de fomento, representações diplomáticas, organismos e programas internacionais; f) Associação Brasileira dos Reitores das Universidades Estaduais e Municipais (ABRUEM) - é uma organização, fundada em outubro de 1991, que reúne 46 universidades públicas brasileiras; g) Associação Brasileira de Educação a Distância (ABED) - é uma sociedade científica, sem fins lucrativos, voltada para o desenvolvimento da educação aberta, flexível e a distância, fundada em 21 de junho de 1995 por um grupo de educadores interessados em educação a distância e em novas tecnologias de aprendizagem; h) Associação Brasileira de Educação (ABE) - criada na década de 20 com o propósito de avaliar suas responsabilidades e deveres em relação aos grandes problemas nacionais de educação; i) Associação Brasileira de Mantenedoras de Ensino Superior (ABMES) - trata-se de uma entidade que representa o ensino superior particular e atua junto ao governo e Congresso Nacional pelos interesses legítimos das instituições educacionais.

\section{Representação de classe}

Existem alguns organismos que representam aqueles que interagem na área de educação. Segue: a) Sindicato dos Professores (SINPRO) - são organizados por todo o país tendo uma representação por estado da federação; b) Sindicato dos Auxiliares de Administração Escolar (SAAE) - organizados por todo o país tendo uma representação por estado da federação; c) União Nacional dos Estudantes (UNE) - organização de representatividade dos estudantes universitários.

\section{Agentes financeiros}

Tendo em vista o grande número de alunos na rede privada, há várias iniciativas para viabilizar a entrada dos alunos. $O$ crédito estudantil pode ser contratado tanto por quem irá iniciar o curso de graduação como por quem já está matriculado na faculdade. Em todas as instituições, assim como no Fies, o estudante só consegue obter o crédito em instituições de ensino parceiras dos programas. Cerca de 70 universidades participam atualmente do Pravaler no Brasil. Já o Bradesco tem parceria com oito instituições de ensino, e 29 faculdades utilizam o serviço da Fundaplub. Seguem algumas iniciativas tanto governamentais como privadas: a) PRAVALER - trata-se do maior programa de crédito universitário privado do país; b) FIES programa do governo federal que financia os estudos do aluno a longo prazo. Tem como principal gestora a 
Caixa Econômica Federal; c) Bancos - os bancos Bradesco, Itaú, Fundaplub administram programas de financiamento para estudantes.

\section{CONCLUSÕES}

Conforme percebe-se pela estrutura da educação no país, há desafios existentes que consideram tanto a esfera pública como a privada. A predominância do meio privado, em número de instituições de ensino e no número de alunos, não é vista como um papel importante e muitas vezes essas instituições sofrem com mudanças legais que ocorrem a todo e qualquer momento, o que muitas vezes prejudica investimentos do setor privado. Ao discutir essa temática não se pode deixar de lado se a educação ocupa ou cumpre o papel que the cabe.

Nesse sentido, pode-se identificar que seriam necessários dois grandes processos de formação que incluem empregos que exigem maior qualificação e uma formação por certificação em massa. No entanto em ambas o que deveria prevalecer não é a finalidade de conseguir o término da formação. A preocupação deveria se valer das competências que foram atribuídas.

Nos EUA, por exemplo, a colaboração entre a universidade e as indústrias já ocorre há algum tempo. No entanto é, sobretudo, a partir da década de 1980 que essa associação toma um impulso significativo, aumentam os níveis de patentes e licenças de conhecimentos produzidos na universidade e sua comercialização ocorre mais rapidamente. Na Europa, conforme Leher (2015), há concepções utilitaristas e instrumentais quanto à produção do conhecimento científico. A análise indica, ainda, forte indução à "cultura empresarial orientada para o mercado e o lucro, e ainda pelo exemplo das universidades empreendedoras e inovadoras dos Estados Unidos da América".

Por força da estrutura da educação no país, é possível perceber que o que passou a nortear foi a busca de lucros, deixando de lado a formação humanística e mesmo suas competências. A relevância econômica, em virtude da alta competição, do ambiente legal e mesmo das imposições acabam fazendo com que sobreviver seja mais importante que as contribuições para os aspectos cognitivos, sociais e culturais do conhecimento.

Tais aspectos somente serão conseguidos se houver um alinhamento entre os organismos que cuidam da educação. Estes devem ter uma coordenação que pense em formar através de competências e não simplesmente em cumprir metas de concluintes do ensino médio. É preciso repensar toda a cadeia e entender os impactos que provém em formar alunos que não estão diretamente prontos para os próximos níveis. Também, é preciso fazer com que o professor esteja preparado para um novo modelo. Este deve estar ajustado à nova geração, a novos meios para educar e preparar o aluno para os níveis seguintes.

\section{REFERÊNCIAS}

BRASIL. Lei n. 9.394, de 20 de dezembro de 1996. Lei de Diretrizes e Bases da Educação Nacional. Brasília: DOU, 1996.
BRASIL. Sinopses estatísticas do Censo da Educação

Superior: 1995-2015. Brasília: MEC, 2015.

COSTA, P. R.; MONTEIRO, R. C. R. V.; SILVA, J. L. G.; OLIVEIRA, E. L.. Mapeamento da Cadeia Produtiva do Ensino Superior e 
Gestão de Seus Elos. Latin American Journal of Business Management, v.6, p.190-215, 2015.

INEP. Instituto Nacional de Estudos e Pesquisas Educacionais. Sinopse da Educação Superior: 2014. Rio de Janeiro: INEP, 2015.

INEP. Instituto Nacional de Estudos e Pesquisas Educacionais. Sinopse da Educação Superior: 2015. Rio de Janeiro: INEP, 2016.
LEHER, R.. Movimentos sociais, padrão de acumulação e crise da universidade. In: REUNIÃO NACIONAL DA ANPEd, 37. Anais. Florianópolis: Associação Nacional de Pósgraduação e Pesquisa em Educação, 2015.

REZENDE, J. B.; SANTOS, A. C.. Cadeia Produtiva do Carvão Vegetal. Belo Horizonte: EPAMIG, 2007.

A CBPC - Companhia Brasileira de Produção Científica (CNPJ: 11.221.422/0001-03) detém os direitos materiais desta publicação. Os direitos referem-se à publicação do trabalho em qualquer parte do mundo, incluindo os direitos às renovações, expansões e disseminações da contribuição, bem como outros direitos subsidiários. Todos os trabalhos publicados eletronicamente poderão posteriormente ser publicados em coletâneas impressas sob coordenação da Sapientiae Publishing, da Companhia Brasileira de Produção Científica e seus parceiros autorizados. Os (as) autores (as) preservam os direitos autorais, mas não têm permissão para a publicação da contribuição em outro meio, impresso ou digital, em português ou em tradução. 